Int. J. Electrochem. Sci., 15 (2020) 5179 - 5192

International Journal of

ELECTROCHEMICAL

SCIENCE

WWW.electrochemsci.org

\title{
Photocatalytic Self-Cleaning Electrochemical Sensor for 4- Nitrophenol detection
}

\author{
Jiabing Chen ${ }^{1,2}$, Youluan Lu ${ }^{1}$, Leshu Huang ${ }^{1}$, Zhen Shi ${ }^{2}$, Yin Zheng ${ }^{1,2, *}$, Xinjian Song ${ }^{2, *}$, \\ Chenyi $W u^{2}$, Zaikun $W u^{3}$ \\ ${ }^{1}$ Hubei Key Laboratory of Biological Resources Protection and Utilization, Hubei, 445000, China \\ ${ }^{2}$ Department of Chemistry, Hubei Minzu University, Enshi, Hubei 445000, China \\ ${ }^{3}$ School of Chemical Engineering \& Pharmacy, Wuhan Institute of Technology, Wuhan, Hubei \\ 430073, China \\ *E-mail: zhengyin0617@163.com ; whxjsong@163.com
}

doi: $10.20964 / 2020.06 .05$

Received: 12 August 2019 / Accepted: 28 February 2020 / Published: 10 May 2020

Electrode fouling and passivation are the main reasons for attenuated the electrochemistry signals. In this work, a renewable electrode for determination of 4-nitrophenol (4-NP) which not only has excellent detection signals but also can be photo-catalytically refreshed to remain the selectivity and sensitivity was been created. The $\mathrm{GO} / \mathrm{TiO}_{2}-\mathrm{CuTCPP}$ composite material was characterized by Transmission electron microscopy (TEM), X-ray diffraction (XRD), electrochemical impedance spectroscopy (EIS), X-ray photoelectron spectroscopy (XPS), Fourier transform infrared spectra (FT-IR). The electrochemical behavior of 4-NP on $\mathrm{GO} / \mathrm{TiO}_{2}-\mathrm{CuTCPP} / \mathrm{GCE}$ was investigated by cyclic voltammetry $(\mathrm{CV})$ and square wave voltammetry (SWV) in $0.2 \mathrm{~mol} / \mathrm{L}$ acetic acid buffer at $\mathrm{pH} 5.5$. The result showed that the $\mathrm{GO} / \mathrm{TiO}_{2}-\mathrm{CuTCPP} / \mathrm{GCE}$ exhibits the higher peak current and photo-catalytic activity to prone the self-cleaning ability. Under the optimal conditions, the oxidation current peak values linearly with the concentration of 4-NP ranging from 0.5 to $100 \mu \mathrm{mol} / \mathrm{L}$, and the detection limit was $0.16 \mu \mathrm{mol} / \mathrm{L}$ (S/N $=3$ ). Moreover, the sensors showed excellent renewable ability under visible light without damaging the electrode microstructure and attenuating electrochemical signals.

Keywords: graphene oxide, titanium dioxide, electrochemical sensor

\section{FULL TEXT}

(C) 2020 The Authors. Published by ESG (www.electrochemsci.org). This article is an open access article distributed under the terms and conditions of the Creative Commons Attribution license (http://creativecommons.org/licenses/by/4.0/). 